\title{
Transbronchial Catheter Aspiration Compared to Forceps Biopsy in the Diagnosis of Peripheral Lung Cancer
}

\author{
K.-J. Franke, G. Nilius, K.-H. Ruhle \\ Department of Pneumology and Critical Care Medicine, Helios Klinik Ambrock, University of Witten/Herdecke, Germany
}

\begin{abstract}
Objective: The usual procedure for obtaining material for histological analysis for the diagnosis of peripheral carcinoma of the lung is transbronchial forceps biopsy (TBB). Not widely spread is acquiring samples for cytological examination by transbronchial catheter aspiration (TBCA). Data were retrospectively collected to determine the diagnostic sensitivity of TBCA in comparison with TBB concerning malignancy.

Methods: We analysed the results of 51 consecutively examined patients (age $68.7 \pm 8.8$ yrs.) applying both methods. 48 of 51 peripheral lesions proved to be malignant, 34 of which measured $>3 \mathrm{~cm}$ in diameter and $14 \leq 3 \mathrm{~cm}$. Fluoroscopy provided guidance in biopsies for both techniques.

Results: The mean diameter of the lesion was $3.7 \pm$ $1.5 \mathrm{~cm}$. We were able to establish a correct diagnosis by TBCA in 36 of 48 patients with lung cancer, and in 21 of 48 patients by TBB $(75 \%$ vs. $44 \%, \mathrm{p}<0.01$, chi-square-test). By combination of both methods 39 of 48 patients were correctly diagnosed. For carcino$\mathrm{ma}>3 \mathrm{~cm}$ the success rate for TBCA was $76 \%$ $(26 / 34)$ and for TBB 56\% (19/34). For carcinoma $\leq 3$ $\mathrm{cm}$ the success rate for TBCA was $71 \%(10 / 14)$ and for TBB 14\% (2/14).

Conclusions: Even in lesions $\leq 3 \mathrm{~cm}$ application of TBCA results in an only marginally lower success rate compared to lesions $>3 \mathrm{~cm}$. Due to the overall high success rate we suggest to apply the easy-to-handle and inexpensive method of TBCA in diagnostic procedure of peripheral lung carcinoma.
\end{abstract}

Key words: lung cancer; transbronchial biopsy; transbronchial catheter aspiration; peripheral pulmonary lesions; bronchoscopy

Abbreviations: BB: bronchial brushing, EBUS: endobronchial ultrasound, ENB: electromagnetic navigation bronchoscopy, TBB: transbronchial forceps biopsy, TBCA: transbronchial catheter aspiration, TBNA: transbronchial needle aspiration

\section{INTRODUCTION}

The most established diagnostic procedure for detecting peripheral lesions of the lung is the extraction of tissue for histological examination by transbronchial forceps biopsy (TBB) under fluoroscopy control with a diagnostic sensitivity between 32 and 57\% [1,2]. Several studies were able to prove an amelioration of success rates by addition of cytological methods such as transbronchial needle aspiration (TBNA), bronchial brushing $(\mathrm{BB})$ and bronchial washing (BW) $[3,4,5]$. For TBNA a significantly higher yield was reported in comparison with TBB $[1,6]$. The high specifity of cytologic methods in lung carcinoma is confirmed [2, 3, 7-10].

A less widely spread technique of acquiring cytological samples is transbronchial catheter aspiration (TBCA) that was introduced 1961 and continued in modernized technique $[11,12]$. Sample material is mechanically mobilized and aspirated through the radiopaque catheter which is pushed forward into the lesion. The blunt distal end of the catheter implies low complication rates, there is no risk to impare the working channel. The costs of this method are low, because the catheter is reusable. It is easy to handle and can be performed outside the expert centers as well.

Diagnostic sensitivity of bronchoscopic methods in lung carcinoma with no corresponding airway abnormalities varies widely between 24 and $82 \%$ [ 6,13$]$, mainly dependent on the size of lesion, largest difference at 3 centimeters $[1,4,6,13]$. Modern, more complex methods of guidance, such as endobronchial ultrasound (EBUS) and electromagnetic navigation bronchoscopy (ENB), can improve success rates especially in small peripheral lesions $<3 \mathrm{~cm}$ that can frequently not be detected under fluoroscopy [13-16]. Disadvantageous are high costs and additional expense relating to the apparatus.

In comparison with TBB, TBCA showed a higher diagnostic sensitivity in a study on 28 cases [17]. The objective of the presented study was to corroborate the diagnostic value of TBCA in endoscopically not visible lung carcinoma compared directly to TBB. An additional goal was to evaluate in which manor the yield of TBCA is affected by the size of the lesion.

\section{Methods}

\section{STUdy Design}

We evaluated 51 consecutive patients between January and December 2004 with pulmonary nodules or mass- 
es detected on the chest radiograph, who as a standard approach underwent both TBB and TBCA. Informed consent was obtained in all patients prior to the procedure. Permission was obtained from the Institutional Review Board at the University of Witten/Herdecke to review and publish patient records retrospectively. Only patients without endobronchial visible tumour at bronchoscopy were included in the study. In every case TBCA was performed first, followed by TBB. The number of TBB and TBCA was noted directly after bronchoscopy. Location of the lesion was determined from the radiographs and the CT. The largest dimension of the lesion in $\mathrm{mm}$ was measured.

\section{BRONCHOSCOPY}

Beside an anaesthesia of the bronchial system with lidocaine ( $2 \%$ solution), midazolam was used in minimum amounts when necessary. Fluoroscopy was provided using a $\mathrm{C}$-arm. We used videoendoscopes with an external diameter of $6.2 \mathrm{~mm}$ (Pentax Europe). Biopsies were performed with regular disposable biopsy forceps and a catheter with a diameter of $2.3 \mathrm{~mm}$, which is visible under fluoroscopy (Wieser, Egenhofen, Germany). We aspirated the cytological sample into the tip of the catheter by a few vigorous backand-forth movements while suction was performed with a $10-\mathrm{ml}$ syringe. The forceps biopsy samples were placed in formalin and the content of the catheter was given into $70 \%$ alcohol and sent in for histological and cytological examination, respectively.

\section{FOLLOW-UP}

Surgical pathologic diagnosis was compared with the bronchoscopic diagnosis in patients who underwent subsequent resection. A clinical follow-up was done for 3 years.

\section{STATISTICAL ANALYSIS}

Results were compared using the chi-square test. Data are presented as mean $\pm \mathrm{SD}$.

\section{RESULTS}

We examined 51 patients with an average age of 68.7 \pm 8.8 yrs. The mean diameter of the lesion was $3.7 \pm$ $1.5 \mathrm{~cm}$. The number of samples obtained by catheter aspiration was $2.8 \pm 1.0$ and the number of samples obtained by forceps biopsy was $3.2 \pm 1.4$.

After bronchoscopy, 20 of 51 patients received a subsequent surgical biopsy, in 3 of 51 patients percutaneous transthoracic biopsy was performed, in 28 of 51 patients clinical follow-up was done for 3 years.

In 12 of 20 cases with surgical biopsy bronchoscopical diagnosis of malignancy was confirmed, in 6 patients with nondiagnostic bronchoscopy surgical biopsy was able to resolve diagnosis of malignancy, 1 tumour was proved by thoracotomy to be benign. There was 1 false positive result by catheter aspiration from the right lower lobe (adeno carcinoma), proved by surgical pathologic diagnosis as chronic pneumonia.

In 1 of 3 cases with percutaneous transthoracic biopsy bronchoscopical diagnosis of malignancy was confirmed, in 2 patients with nondiagnostic bronchoscopy percutaneous transthoracic biopsy was able to resolve diagnosis of malignancy.

In 26 of 28 patients bronchoscopical diagnosis of lung cancer was corroborated by clinical follow up for 3 years. 1 patient with nondiagnostic bronchoscopy died of lung cancer and 1 lesion was remarked as benign, because the tumor size had not increased after 3 years. Both patients had not agreed to a surgical procedure.

Sensitivity and specificity of bronchoscopy in relation to malignancy proved by surgical biopsy, trans-

Table 1. Yield by bronchoscopy in relation to malignancy proved by surgical biopsy, transthoracic biopsy and clinical follow-up.

Yield by bronchoscopy $n=51$

\begin{tabular}{llll}
\hline & $\begin{array}{l}\text { Surgical biopsy } \\
\mathrm{n}=20\end{array}$ & $\begin{array}{l}\text { Transthoracic biopsy } \\
\mathrm{n}=3\end{array}$ & $\begin{array}{l}\text { Clinical follow-up } \\
\mathrm{n}=28\end{array}$ \\
True positive & $12 / 20$ & $1 / 3$ & $26 / 28$ \\
False positive & $1 / 20$ & $0 / 3$ & $0 / 28$ \\
True negative & $1 / 20$ & $0 / 3$ & $1 / 28$ \\
False negative & $6 / 20$ & $2 / 3$ & $1 / 28$ \\
\hline
\end{tabular}

Table 2. Size of peripheral lung cancer and yield.

\begin{tabular}{|c|c|c|c|c|}
\hline \multirow[b]{2}{*}{ Carcinoma, Size } & \multirow[b]{2}{*}{ Carcinoma, No. } & \multicolumn{2}{|c|}{ Diagnostic sensitivity (\%) by: } & \multirow[b]{2}{*}{ Combination (TBB/TBCA) } \\
\hline & & Forceps biopsy (TBB) & Catheter aspiration (TBCA) & \\
\hline $\begin{array}{l}\text { All, } \\
38,3 \pm 14,8 \mathrm{~mm}\end{array}$ & 48 & 44 & 75 & 81 \\
\hline $\begin{array}{l}\text { Carcinoma } \leq 3 \mathrm{~cm} \\
20,6 \pm 6,5 \mathrm{~mm}\end{array}$ & 14 & 14 & 71 & 71 \\
\hline $\begin{array}{l}\text { Carcinoma }>3 \mathrm{~cm} \\
45,6 \pm 10,4 \mathrm{~mm}\end{array}$ & 34 & 56 & 76 & 85 \\
\hline
\end{tabular}


Table 3. Yield by catheter aspiration technique $(\mathrm{n}=51)$.

\begin{tabular}{ll}
\hline True positive & False positive \\
$36 / 51(70,59 \%)$ & $1 / 51(1,96 \%)$ \\
True negative & False negative \\
$2(3,92 \%)$ & $12(23,53 \%)$ \\
\hline
\end{tabular}

Table 4. Location of the peripheral lung cancer.

\begin{tabular}{llll}
\hline & & \multicolumn{2}{l}{$\begin{array}{l}\text { Yield for malignant } \\
\text { disease obtained by: }\end{array}$} \\
& $\mathrm{n}=48$ & $\begin{array}{l}\text { Forceps } \\
\text { biopsy } \\
\text { (TBB) }\end{array}$ & $\begin{array}{c}\text { Catheter } \\
\text { aspiration } \\
\text { (TBCA) }\end{array}$ \\
\hline Left upper lobe & 14 & 7 & 10 \\
Right upper lobe & 17 & 4 & 12 \\
Middle lobe & 2 & 1 & 2 \\
Left lower lobe & 5 & 4 & 4 \\
Right lower lobe & 10 & 5 & 8 \\
\hline
\end{tabular}

thoracic biopsy and clinical follow-up are shown in Table 1.

Collectively, 48 of 51 patients were taken sick with lung cancer. Bronchoscopical sampling achieved a definitive diagnosis in 39 of 48 patients with lung cancer $(81 \%)$, in 21 cases the histological procedure was diagnostic (44\%), and in 36 the cytological method $(75 \%)$. The yield of the cytological procedure of TBCA was significantly higher than the yield obtained by TBB (75\% vs. $44 \%, \mathrm{p}<0.001$, chi-square-test).

Table 2 shows the diagnostic sensitivity in relation to malignancy and the effect of size on the yield from bronchoscopy. Diagnostic yield was higher for lesions defined as mass ( $>3 \mathrm{~cm}$ size; $29 / 34,85 \%$ ) than for lesions defined as nodules $(\leq 3 \mathrm{~cm} ; 10 / 14,71 \%)$. The difference of the success rates of TBCA compared with TBB was evidently greater in lesions $\leq 3 \mathrm{~cm}$ $(10 / 14,71 \%$ vs. $2 / 14,14 \%)$ than in lesions $>3 \mathrm{~cm}$ in diameter $(26 / 34,76 \%$ vs. $19 / 34,56 \%)$.

Sensitivity and specificity of catheter aspiration technique in our study are shown in Table 3.

The localisation of the peripheral nodule or mass was the left upper lobe in 14 patients, the right upper lobe in 17 patients, the middle lobe in 2 , the left lower lobe in 5 and the right lower lobe in 10. Table 4 shows the yield by location of the peripheral lesion in relation to malignancy.

No significant complications occured in our series with either TBCA or TBB, such as pneumothorax or bleeding requiring further action than the instillation of noradrenalin.

\section{Discussion}

1. Our study shows a significantly higher diagnostic sensitivity of TBCA compared to TBB concerning malignancy. On a larger sample and in smaller lesions than presented before [17], the data corroborates the superiority of TBCA.
2. Applying TBCA success rates are only marginally lower in lesions $\leq 3 \mathrm{~cm}$ in comparison to lesions $>3 \mathrm{~cm}$ (71 vs. $76 \%)$.

\section{TBCA COMPARED TO TBB:}

Success rates of TBB under fluoroscopy for peripheral lung carcinoma vary without regard to the size of the lesion between 30 and $57 \%[2,18]$. We achieved a sensitivity of $45 \%$ at average lesion size of $3.8 \pm 1.5$ $\mathrm{cm}$.

Previously TBNA has been the only cytological method to achieve a higher sensitivity in comparison with TBB (success rates concerning malignancy TBNA vs. TBB: 46 vs. $32 \%, 62 \%$ vs. $38 \%, 69 \%$ vs. $54 \%)[1,6,7]$. Besides the fact that less material is required for cytological confirmation of diagnosis per se, the significantly higher success rate of TBCA may result from the application of continuous catheter suction that allows to collect not only local sample material, but also from a larger area of the region of interest. The volume of biopsy of TBCA is augmented by strong suction [12].

Most carcinoma are located in the upper lobes, in our study $14 / 48$ in the left, $17 / 48$ in the right upper lobe. The biggest difference of success rates between $\mathrm{TBB}$ and TBCA concerning lobar localisation arises in the right upper lobe: TBB yields a diagnostic sensitivity of $4 / 17$, whereas TBCA reaches a sensitivity concerning malignancy of $12 / 17$. This can be explained by a higher flexibility of the catheter compared to the forceps allowing a better access of strongly distorted subsegmental ostia.

Another advantage of TBCA compared to TBB may be increasing difficulties to open the forceps the more the airway is narrowing, while the tip of the catheter probably does not lose its ability to injure the surface of the lesion. TBNA and TBCA both are underutilized procedures $[19,20]$. Concerning TBCA, in spite of its easy handling, little risk of damaging the bronchoscope and low cost. The price of the catheter is $37,37 \mathrm{EUR}$, it is reusable up to 40 times.

\section{TBCA YIELD IN LESIONS $\leq 3 \mathrm{CM}$}

For lung cancer $<2 \mathrm{~cm}$ success rates reported for TBB are between 15 and $35 \%$ [21], the success rate in our study was $14 \%$ for malignant lesions $\leq 3 \mathrm{~cm}$. This may be due to the fact, that small lesions are frequently not visible in fluoroscopy, so that only regions of interest can be explored. More recently developed methods of guidance show outstanding sensitivity in these cases. Using EBUS in combination with a guide sheath, 74\% $(40 / 54)$ of peripheral lesions $\leq 2 \mathrm{~cm}$ invisible in fluoroscopy were diagnosed by TBB and BB [13]. In another study 54 lesions were invisible in fluoroscopy, 48 of these were localized by EBUS; success rate of TBB was $70 \%(38 / 48)$ at an average size of the lesions of $2.2 \mathrm{~cm}$ [15]. Recently reported, by use of EBUS with a guide sheath without fluoroscopy the diagnostic sensitivity for lesions with diameters of 2 to $3 \mathrm{~cm}$ was $57.9 \%(22 / 38)$, adding fluoroscopy the yield was $81.6 \%$ (31/38). Most of the lesions were located in the right upper lobe, with lowest diagnostic yield [22]. 
A further new method, electromagnetic navigation bronchoscopy (ENB), allows to direct the sampling tool directly towards the peripheral lesion. At an average size of $2.28 \mathrm{~cm}$ per lesion a success rate of $74 \%$ was achieved using $\mathrm{BB}, \mathrm{TBB}$ or TBNA for sampling methods; for tumor sizes 0 to $3 \mathrm{~cm}$ diagnostic gain was $72.09 \%$, for peripheral lesion sizes $>3 \mathrm{~cm}$ it was $81.8 \%$ [16]. While 84 of 92 peripheral lesions were $\leq 3$ $\mathrm{cm}$, another study shows an overall positive diagnostic yield of 67\% using ENB without fluoroscopy [23].

Combining both EBUS and ENB the yield of TBB without fluoroscopic guidance was $88 \%$, independent of lesion size or lobar distribution [24].

In our study we achieved diagnostic sensitivity of $71 \%$ vs. $76 \%$ concerning malignancy by TBCA in peripheral lesions of 0 to $3 \mathrm{~cm}$ size vs. $>3 \mathrm{~cm}$ with fluoroscopy and without general anesthesia. However, the number of peripheral lung carcinoma $\leq 3 \mathrm{~cm}$ was only 14,9 of which were located in the upper lobes. Success rate by TBCA was 5 out of 9 . All 5 carcinoma $\leq 3$ $\mathrm{cm}$ of other localizations were diagnosed by TBCA. This confirms the difficulty of diagnosing small lesions especially in apical upper lobe segments $[4,6,15]$.

In contrast, there is a higher difference in success rates of TBNA under fluoroscopy depending on tumor size: peripheral lesions $>3 \mathrm{~cm}$ were reached, compared to lesions $<3 \mathrm{~cm}$ in 69 vs. $50 \%(\mathrm{n}=37)$ [6] respectively 67 vs. $28 \%(n=114)$ [1]. One reason can be the lesser flexibility of the needle, another the fact that TBNA allows targeted sampling only.

\section{CONCLUSIONS}

TBCA seems to represent an efficient and easy-tohandle method for diagnosis of peripheral lung carcinoma with a relatively good diagnostic yield independent of lesion size, which can be performed outside the expert centers as well. Catheters are inexpensive with low costs per case of the whole procedure. Due to these advantages, the use of this method could be included in a sequential concept, that peripheral tumours could first be diagnosed by TBCA under fluoroscopy. In case of negative results, in another step, diagnosis could be established by EBUS- guided transbronchial lung biopsy and/or ENB.

Conflicts of interest: Karl-Josef Franke, Georg Nilius and Karl-Heinz Ruehle declare, that no financial or other potential conflicts of interest exist in the subject matter.

\section{REFERENCES}

1. Reichenberger F, Weber J, Tamm M, Bolliger CT, Dalquen P, Perruchoud AP, Solèr M. The value of transbronchial needle aspiration in the diagnosis of peripheral pulmonary lesions. Chest 1999; 116: 704-8.

2. Baaklini WA, Reinoso MA, Gorin AB, Sharafkaneh A, Manian P. Diagnostic yield of fiberoptic bronchoscopy in evaluating solitary pulmonary nodules. Chest 2000; 117 : 1049-54.

3. Mak VHF, Johnston IDA, Hetzel MR, Grubb C. Value of washings and brushings at fibreoptic bronchoscopy in the diagnosis of lung cancer. Thorax 1990; 45: 373-6.

4. Chechani V. Bronchoscopic diagnosis of solitary pulmonary nodules and lung masses in the absence of endobronchial abnormality. Chest 1996; 109: 620-5.
5. Bilaceroglu S, Kumcuoglu Z, Alper H, Osma E, Cagirici U, Gunel O, Bayol U, Celikten E, Perim K, Kose T. CT bronchus sign-guided bronchoscopic multiple diagnostic procedures in carcinomatous solitary pulmonary nodules and masses. Respiration 1998; 65: 49-55.

6. Katis $\mathrm{K}$, Inglesos E, Zachariadis E, Palamidas P, Paraskevopoulos I, Sideris G, Tamvakopoulou E, Apostolopoulou F, Rasidakis A. The role of transbronchial needle aspiration in the diagnosis of peripheral lung masses or nodules. Eur Respir J 1995; 8: 963-6.

7. Gasparini S, Ferretti M, Secchi EB, Baldelli S, Zuccatosta L, Gusella P. Integration of transbronchial and percutaneous approach in the diagnosis of peripheral pulmonary nodules or masses. Chest 1995; 108: 131-7.

8. Lee C-H, Wang C-H, Lin M-C, Tsao TCY, Lan R-S, Tsai Y-H, Kuo H-P. Multiple brushings with immediate Riu `s stain via flexible fibreoptic bronchoscopy without fluoroscopic guidance in the diagnosis of peripheral pulmonary tumours. Thorax 1995; 50: 18-21.

9. Agusti C, Xaubet A, Monton C, Sole M, Soler N, Carrion $\mathrm{M}$, Rodriguez Roisin R. Induced sputum in the diagnosis of peripheral lung cancer not visible endoscopically. Respir Med 2001; 10: 822-8.

10. Liao W-Y, Jerng J-S, Chen K-Y, Chang Y-L, Yang P-C, Kuo S-H. Value of imprint cytology for ultrasound-guided transthoracic core biopsy. Eur RespirJ2004; 24: 905-9.

11. Friedel H. Die Katheterbiopsie des peripheren Lungenherdes. Tuberkulosebibliothek Nr99 Barth, Leipzig 1961.

12. Atay Z, Hammesfahr R, Worch R, Ekinci C. Cytological diagnosis of peripheral lung tumours by combined evaluation of catheter and aspiration biopsies. Prax Pneumol 1981; 35: 220-4.

13. Kurimoto N, Miyazawa T, Okimasa S, Maeda A, Oiwa H, Miyazu Y, Murayama M. Endobronchial ultrasonography using a guide sheath increases the ability to diagnose peripheral pulmonary lesions endoscopically. Chest 2004; 126: 959-65.

14. Herth FJF, Ernst A, Becker HD. Endobronchial ultrasound-guided transbronchial lung biopsy in solitary pulmonary nodules and peripheral lesions. Eur Respir J 2002; 20: 972-4.

15. Herth FJF, Eberhardt R, Becker HD, Ernst A. Endobronchial ultrasound-guided transbronchial lung biopsy in fluoroscopically invisible solitary pulmonary nodules a prospective trial. Chest 2006; 129: 147-50.

16. Gildea TR, Mazzone PJ, Karnak D, Meziane M, Mehta AC. Electromagnetic navigation diagnostic bronchoscopy - a prospective study. Am J Respir Crit Care Med 2006; 174: 982-9.

17. Franke KJ, Nilius G, Ruehle KH. Transbronchial biopsy in comparison with catheter aspiration in the diagnosis of peripheral pulmonary nodules. Pneumologie 2006; 60: 710.

18. Torrington KG, Kern JD. The utility of fiberoptic bronchoscopy in the evaluation of the solitary pulmonary nodule. Chest 1993; 104: 1021-4.

19. Haponik EF, Shure D. Underutilization of transbronchial needle aspiration: experiences of current pulmonary fellows. Chest 1997; 112: 251-3.

20. Franke KJ, Nilius G, Rühle KH. Frequency of cytological procedures in diagnostic bronchoscopy of peripheral pulmonary nodules and masses. Pneumologie 2006; 60: 663-6.

21. Shure D. Transbronchial biopsy and needle aspiration. Chest 1989; 95: 1130-8.

22. Yoshikawa M, Sukoh N, Yamazaki K, Kanazawa K, Fukumoto S, Harada M, Kikuchi E, Munakata M, Nishimura M, Isobe $H$. Diagnostic value of endobronchial ultrasonography with a guide sheath for peripheral pulmonary lesions without $\mathrm{x}$-ray fluoroscopy. Chest 2007; 131: 1788-93. 
23. Eberhardt R, Anantham D, Herth F, Feller-Kopman D, Ernst A. Electromagnetic navigation diagnostic bronchoscopy in peripheral lung lesions. Chest 2007; 131: 1800-5.

24. Eberhardt R, Anantham D, Ernst A, Feller-Kopman D, Herth F. Multimodality bronchoscopic diagnosis of peripheral lung lesions. Am J Respir Crit Care Med 2007; 176: 36-41.

Received: July 14, 2008 / Accepted: September 26, 2008
Address for correspondence:

Karl-Josef Franke, MD

Department of Pneumology and Critical Care Medicine Helios Klinik Ambrock

University of Witten/Herdecke,

Ambrocker Weg 60

58091 Hagen

Germany

Phone: +49-2331/974201

Fax: $\quad+49-2331 / 974209$

e-mail: karl-josef.franke@helios-kliniken.de

Georg Nilius, MD

e-mail: georg.nilius@helios-kliniken.de

Karl-Heinz Ruhle, MD, Professor,

e-mail: klinik-ambrock.pneumo@t-online.de 